\title{
A MORPHOMETRICAL STUDY OF BRANCHING PATTERN AND ANATOMICAL RELATIONSHIPS OF THE FACIAL NERVE ON THE FACE
}

Naveen Kumar B. D' ${ }^{1}$ Manjunath C. S², Antony Sylvian D’Souza ${ }^{3}$

HOW TO CITE THIS ARTICLE:

Naveen Kumar B. D, Manjunath C. S, Antony Sylvian D'Souza. "A Morphometrical Study of Branching Pattern and Anatomical Relationships of the Facial Nerve on the Face". Journal of Evolution of Medical and Dental Sciences 2014; Vol. 3, Issue 08, February 24; Page: 2057-2065, DOI: 10.14260/jemds/2014/2102

ABSTRACT: BACKGROUND \& AIM OF THE STUDY: The facial nerve gives off five main terminal branches within the substance of parotid gland. They diverge within the gland and supply the muscles of facial expression. Distinctive anastomotic patterns has been previously studied and reported. These anastomoses have pragmatic significance in surgical terms. The purpose of our study is to review the branching pattern of the facial nerve on the face and evaluate the variant anatomical relationships with adjacent structures. MATERIALS\& METHODS: The study was done at Kasturba Medical College, Manipal and Hassan institute of medical sciences, Hassan. The facial nerve was dissected on thirty cadavers bilaterally (60 sides). The five terminal branches were observed from their point of origin in the parotid gland and traced to their termination. The distances from the neighboring structures were measured to elucidate anatomical relations further. The results obtained were analyzed and compared with the previous studies. RESULTS: Wide variation in the branching pattern of facial nerve was noted. CONCLUSION: The knowledge of variant relations of the facial nerve branches will be of utmost importance for the maxillofacial and plastic surgeons for the preservation of the facial nerve in surgeries like parotidectomy, reconstructive surgeries of the face etc. The variations in the branching pattern can also presumably explain why accidental or deliberate division of a particular branch often fails to result in the anticipated facial nerve weakness.

KEYWORDS: FN-facial nerve, LC-lateral canthus, CT-center of tragus, MP-midpoint, UB-upper buccal, LB-lower buccal, MM-marginal mandibular, SMAS-superficial musculoaponeurotic system.

INTRODUCTION: Identification and preservation of facial nerve along with the surrounding anatomic tissue is required in Parotid tumor surgery, Rhytidectomy (facelift surgery), Facial plastic and reconstructive surgery. Extra parotid course of the facial nerve is studied extensively with cadaveric dissections. Distances of the branches from anatomic landmarks, are not always similar during surgery.

The aim of our study was to evaluate the variant anatomical relationships of the branches with adjacent structures. In addition, to assess the branching patterns of the facial nerve at the exit point from parotid gland at a vulnerable location that a surgeon would encounter during aforementioned procedures.

Baker \& Conley, 1979 reported incidence of facial nerve injury is $0.4-2.6 \%$ in face lift surgery.

Risk for facial nerve injury has been reported to be increased with the inclusion of superficial musculoaponeurotic system (SMAS) elevation as compared with a skin-only face lift. SMAS is a composite fibro fatty layer of collagen, elastic and muscle fibers derived from primitive platysma. Elevated superficial to the parotid gland. 


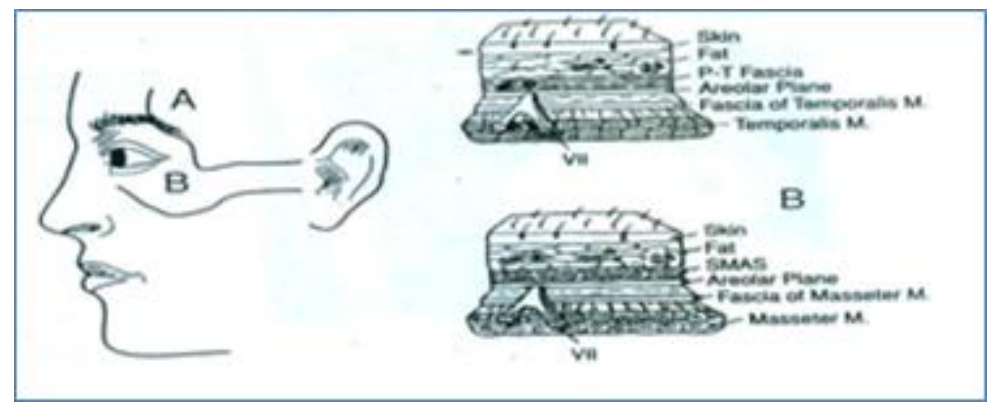

In elevating the SMAS anterior to the parotid gland, the facial nerve is at risk of injury as its branches emerge from the anterior edge of the parotid gland (Wilhelmi et al., 2003)1.

Branches are identified more accurately by the termination in the facial muscles. Location at their exit points from parotid gland may give a clue to identification of the branch. May be controversy in identification some of the branches at this point, Consequence of division of any facial nerve branch ultimately will result in paralysis of facial muscles hence to be taken care of during surgery.
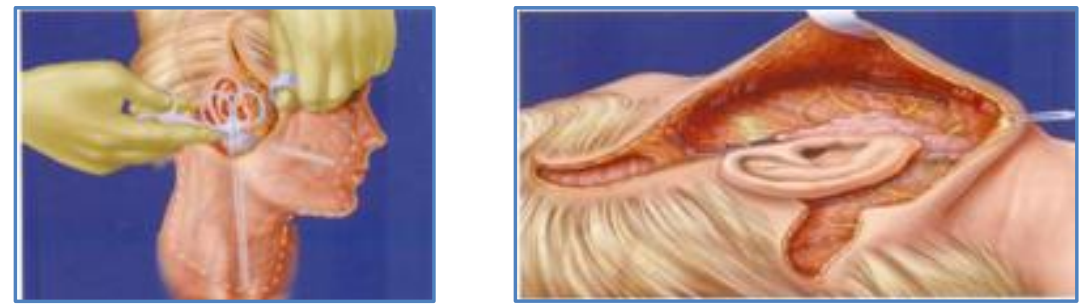

\section{MATERIALS AND METHOD:}

- We dissected 30 formalin embalmed cadavers bilaterally that were free from any gross craniofacial malformations.

- After the facial nerve branches were identified distally to the anterior margin of the parotid gland, further dissection proceeded peripherally.

- This study consists of two investigations concerning distribution of the facial nerve.

1. Morphometry was performed following the method of Saylam et al (2006)2.

2. The branching pattern of the facial nerve was observed.

- All measurements were made using digital calipers and the data was presented in tabular format.

\section{The five distinct branches were identified:}

- Temporal: above lateral canthus

- Zygomatic: below lateral canthus (Qi et. al.,3)

- Buccal: typically lies below the duct

- Marginal mandibular: across the body of the mandible

- Cervical: from the lower part of the parotid gland and runs anteroinferiorly under platysma to the front of the neck (Standring et al, 2008) ${ }^{4}$. 

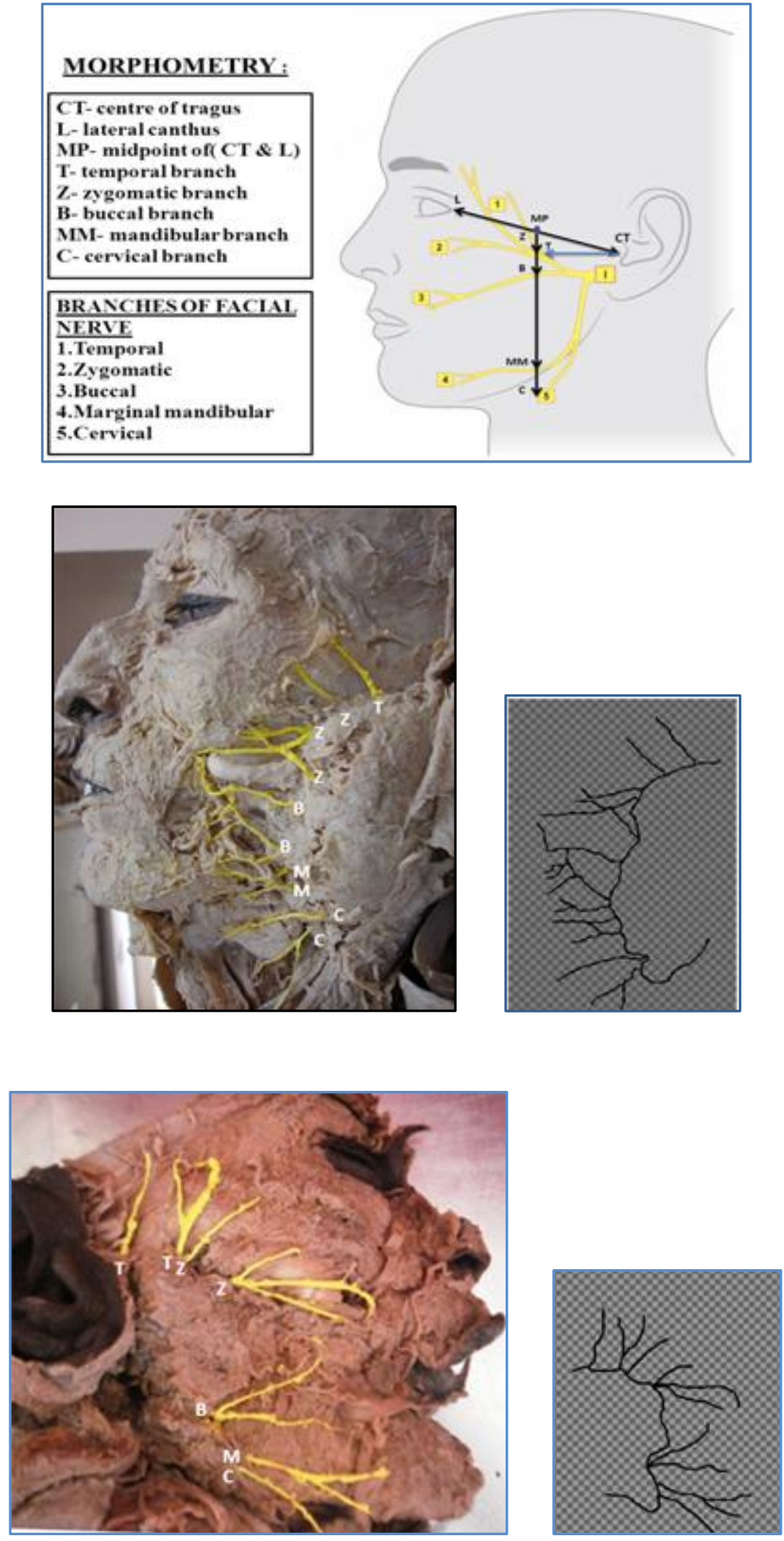


\section{ORIGINAL ARTICLE}
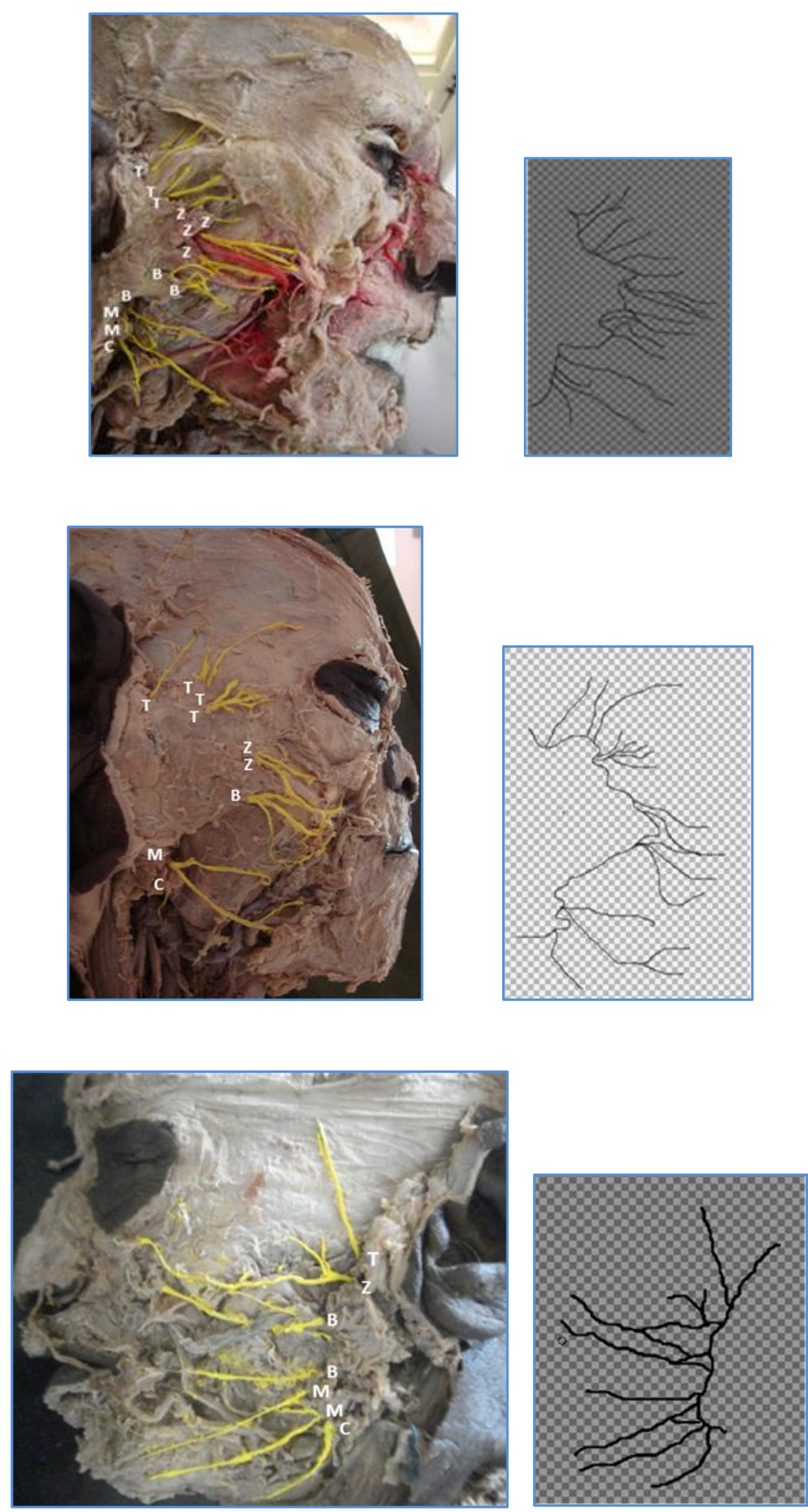


\section{ORIGINAL ARTICLE}

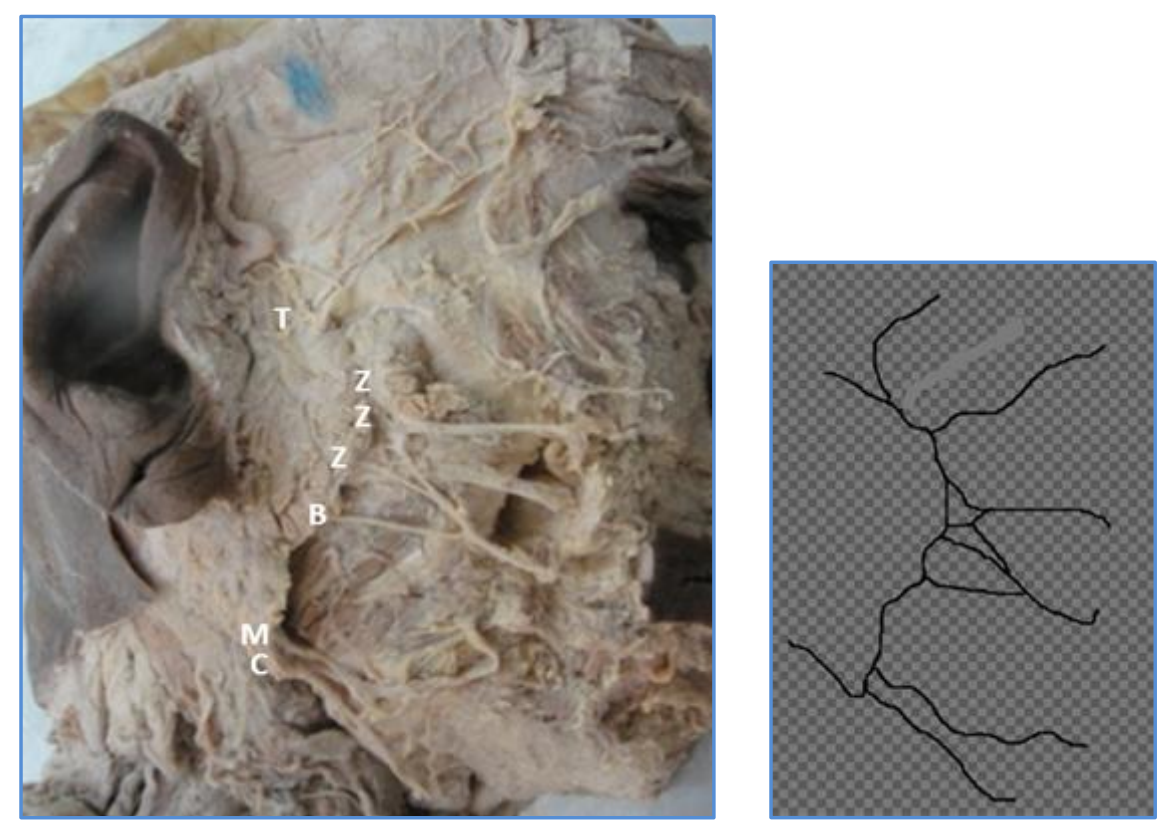

OBSERVATIONS:

\begin{tabular}{|c|c|c|c|c|}
\hline & & $\begin{array}{c}\text { MEAN } \\
(\mathrm{CM})\end{array}$ & $\begin{array}{c}\text { STANDARD } \\
\text { DEVIATION } \\
\text { (CM) }\end{array}$ & $\begin{array}{c}\text { RANGE } \\
\text { (CM) }\end{array}$ \\
\hline Tragus to lateral canthus & CT-LC & 7.87 & 0.42 & $7.2-8.4$ \\
\hline Midpoint & MP & 3.94 & 0.21 & $3.6-4.2$ \\
\hline Tragus to temporal & CT-T & 2.16 & 0.49 & $1.3-3.1$ \\
\hline Midpoint to zygomatic & MP-Z & 1.3 & 1.02 & $0.2-3.9$ \\
\hline Midpoint to upper buccal & MP-UB & 2.9 & 0.63 & 2.1-4.1 \\
\hline Midpoint to lower buccal & MP-LB & 4.73 & 1.15 & $2.6-7.2$ \\
\hline Midpoint to marginal mandibular & MP-MM & 7.36 & 0.85 & $6.4-9.1$ \\
\hline Midpoint to cervical & MP-C & 8.53 & 0.9 & $7.3-10.1$ \\
\hline
\end{tabular}

\begin{tabular}{|c|c|c|c|c|c|c|c|c|c|}
\hline \multicolumn{2}{|c|}{ TEMPORAL } & ZYGOMATIC & \multicolumn{2}{c|}{ BUCCAL } & \multicolumn{2}{c|}{ M.MANDIBULAR } & CERVICAL \\
\hline T-1 & $33.32 \%$ & Z-1 & $25 \%$ & B-1 & $8.32 \%$ & MM-1 & $83.3 \%$ & C-1 & $91.6 \%$ \\
\hline T-2 & $50 \%$ & Z-2 & $17.5 \%$ & B-2 & $50 \%$ & MM-2 & $17.5 \%$ & C-2 & $8.32 \%$ \\
\hline T-3 & $8.32 \%$ & Z-3 & $33.32 \%$ & B-3 & $25 \%$ & MM-3 & - & C-3 & - \\
\hline T-4 & $8.32 \%$ & Z-4 & $17.5 \%$ & B-4 & $17.5 \%$ & MM-4 & - & C-4 & - \\
\hline \multicolumn{8}{|c|}{ Table 2:Showing the frequency of branches of facial nerve } \\
\hline
\end{tabular}




\section{DISCUSSION:}

\begin{tabular}{|l|c|c|c|c|c|}
\hline & T & Z & B & MM & C \\
\hline Mean(cm) & 1.73 & 2.97 & 2.33 & 1.2 & 1.13 \\
\hline Standard deviation(cm) & 0.93 & 0.91 & 0.7 & 0.4 & 0.34 \\
\hline Minimum number & 1 & 1 & 1 & 1 & 1 \\
\hline Maximum number & 4 & 4 & 3 & 2 & 2 \\
\hline Baker \&clonley, 1979 & 3 & 3 & 3 & 3 & 1 \\
\hline
\end{tabular}

Table showing the number of branches of facial nerve

\begin{tabular}{|c|c|c|}
\hline $\begin{array}{c}\text { ZYGOMATIC } \\
\text { BRANCH }\end{array}$ & SAYLAM & PRESENT STUDY \\
\hline $\mathbf{Z - 1}$ & $4.5 \%$ & $25 \%$ \\
\hline $\mathbf{Z}-2$ & $69.7 \%$ & $17.5 \%$ \\
\hline $\mathbf{Z}-3$ & $25.8 \%$ & $33.3 \%$ \\
\hline $\mathbf{Z}-\mathbf{4}$ & - & $17.5 \%$ \\
\hline
\end{tabular}

Table showing the frequency of zygomatic branch

\begin{tabular}{|c|c|c|}
\hline $\begin{array}{c}\text { BUCCAL } \\
\text { BRANCH }\end{array}$ & YOUNG12 & $\begin{array}{c}\text { PRESENT } \\
\text { STUDY }\end{array}$ \\
\hline B-1 & $4 \%$ & $8.32 \%$ \\
\hline B-2 & $17 \%$ & $50 \%$ \\
\hline B-3 & $52 \%$ & $25 \%$ \\
\hline B-4 & - & $17 \%$ \\
\hline
\end{tabular}

Table showing the frequency of buccal branch

\begin{tabular}{|c|c|c|}
\hline MARGINAL MANDIBULAR & EKINCI $^{13}$ & PRESENTSTUDY \\
\hline MM-2 & $4 \%$ & $17.5 \%$ \\
\hline
\end{tabular}

Table showing the frequency of marginal mandibular branch

Zygomatic branch at risk in preauricular region in temporo-mandibular joint surgery.

Over zygomatic arch in facial trauma.Temporal and zygomatic branches in orbital reconstruction in cosmetic procedures. Temporal in brow lift surgery (Schmidt et al, 2001).Distal to the parotid gland, danger areas where nerve branches became superficial were distal temporal, lower buccal, upper mandibular branches over the masseter muscle, marginal mandibular as it crossed the facial artery (Rudolph, 1990) 5 .

Alternatively 3 danger zones are temporal, marginal mandibular and midfacial region (Wilhelmi et al., 2003).

Campero A et al 20086, conducted to clarify the relationships between the extracranial portion of the facial nerve(FN) and the zygomaticarch (ZA).In a vertical plane just anterior to the tragus, the distance from the superior edge of the ZA to the facial nerve (FN) is, on average, 26.88 
$\mathrm{mm}$. The FN then courses superiorly and anteriorly, crossing the ZA $18.65 \mathrm{~mm}$ anterior to the tragus on average. This so called facial-zygomatic triangle represents the area where surgical dissection can be performed with no risk of damaging the FN. Thus, the closer one stays to the tragus, the lesser the risk of damaging the FN below the ZA. If the incision is carried out on a vertical plane closer to the tragus, the skin can be safely cut up to $2 \mathrm{~cm}$ below the ZA. Present study findings are consistent $(2.16 \mathrm{~mm}$ not within $18 \mathrm{~mm})$ and it is the safe area.

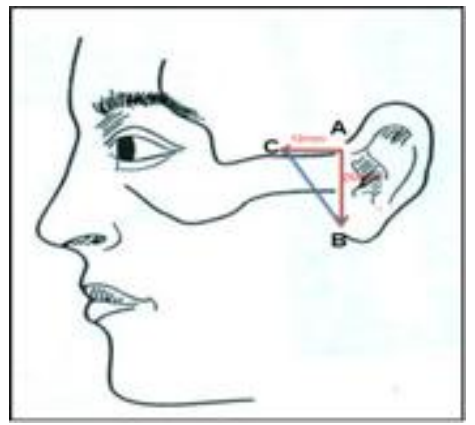

Saylam C et al $2006^{2}$, has mentioned a total of $69.7 \%$ of the cadavers had two branches, $25.8 \%$ had three branches, and $4.5 \%$ had a single zygomatic branch. The mean horizontal distance of the zygomatic branch (the most upper one) as it emerged from the anterior border of the parotid gland and the tragus was $30.71 \mathrm{~mm}$, whereas the mean vertical distance of the zygomatic branch from the midpoint between the tragus and the lateral palpebral commissure was $19.29 \mathrm{~mm}$. The branching patterns with the buccal branches were reported.in present study the shows the inconsistent with the measurements of 1.3+/_1.02.so application of the results in the facial surgery is safe with present measurements. There were no statistical differences between the left and right sides or between the sexes.

Saylam et al $2006^{7}$, has mentioned, the buccal branches of the facial nerve are very vulnerable to surgical injury because of its location in the midface. For this reason, the surgeons who are willing to operate on this area should have a true knowledge about the anatomy of these branches.Measurements of present study also states buccal branches are variable in position, so they are dangerous in the midface region in facial surgery.

Saylam et al $2007^{8}$, has studied the location of marginal mandibular branch(MMBFN) of facial nerve. The relationships between the MMBFN and the inferior border of the mandible were recorded and analyzed. We found that posterior to the facial artery, the MMBFN ran above the inferior border of the mandible in 37 (74\%) of the specimens. In 11 (22\%) specimens, below the inferior border of the mandible. The MMBFN is one of the most vulnerable branches to surgical injury because of its location. Measurements of this study show MMBFN is safe in facial surgery. For this reason, the surgeons who are willing to operate on this area, especially for the rhytidectomies, should have a true knowledge about the anatomy of this branch.

Schmidt BL et al $2001^{9}$, has used landmark as lateral canthus and studied temporal branch. The temporal branch was an average of $2.85+/-0.69 \mathrm{~cm}$ superior to the lateral canthus and an average of $2.54+/-0.43 \mathrm{~cm}$ lateral to the lateral canthus as it courses into the orbicularis oculi muscle. the mean vertical distance between the temporal and zygomatic nerves was $1.72+/-0.62 \mathrm{~cm}$. Present study shows the slight variation in the measurements because of the number of temporal and 
zygomatic branches also varies.so Incisions superior or inferior and parallel to the course of the facial nerve, can provide access to the frontozygomatic suture and the superior and lateral orbit without damaging its branches.

Gosian AK et al 199710, studied temporal branch of the facial nerve and used landmark as 3-D between two layers of temporal region, and states that the temporal branch is not a single nerve branch but consists of multiple rami that cross the zygomatic arch anywhere for over half the length of its inferior border.

Wilhelmi et al $2003^{1}$, studied temporal branch of facial nerve by using landmarks as anterior edge of parotid gland from tragus and mesenteric tuberosity along the zygomatic arch, The risk for facial nerve injury has been reported to be increased with the inclusion of superficial musculoaponeurotic system (SMAS) elevation as compared with a skin-only face lift. The facial nerve courses through the parotid gland. The SMAS is elevated superficial to the parotid gland. However, in elevating the SMAS anterior to the parotid gland, the facial nerve is at risk of injury where its branches emerge from the anterior edge of the parotid gland.

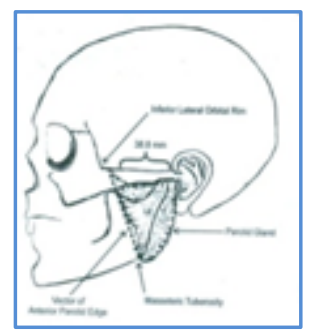

Sekiya T et al 199011, studied the frontotemporal branch of the facial nerve by using landmark as auditory canal. Incising the frontotemporal branch of the facial nerve could be avoided by identifying the crossing point of the frontotemporal branch of the facial nerve on the superior border of the zygomatic arch. The crossing points were investigated and in most cases they existed between $2 \mathrm{~cm}$ and $6 \mathrm{~cm}$ from the anterior border of the external auditory canal. Another important point to preserve the facial nerve is to conserve the layer in which the facial nerve is included.

There were no statistical differences between the left and right sides or between the sexes.

Therefore, the surgical anatomy in the region of the zygomatic arch and temporal area was reviewed in detail. This knowledge is crucial for neurosurgeons to dissect precisely in this region without causing postoperative facial palsy.

\section{CONCLUSION:}

1. The knowledge of variant relations of the nerves will be of utmost importance for the surgeons for preservation offacial nerve in surgeries like maxillofacial, parotidectomy, facial plastic, reconstructive, rhytidectomy on the face and temporomandibular joint surgery etc.

2. Accidental division of particular branch often resulting in the anticipated facial muscle weakness and possible medicolegal consequences on surgeon will be avoided.

\section{REFERENCES:}

1. Wilhelmi BJ, Mowlavi A, NeumeisterMW.The safe face lift with bony anatomic landmarks to elevate the SMAS. PlastReconstr Surg. 2003 Apr 15;111(5):1723-6 
2. SaylamC. Anatomic guides to precisely localize the zygomatic branches of the facial nerve.Craniosurg.2006 Jan;17(1):50-3

3. Qi XD, Hu ZQ, Gao JH, Qiao Q. Microanatomy study of facial nerve distribution at the temporal region for safe facelifting.

4. Standring S. (ED.). Gray's Anatomy. The Anatomical Basis of Clinical Practice. New York. Elsevier Churchill Livingstone. 2005. pp.1014-1017.

5. Rudolph R.Depth of the facial nerve in face lift dissections. PlastReconstr Surg. 1990 Apr; 85(4):537-44.

6. CamperoA.Facio-zygomatictriangle:a relationship between the extracranial portion of facial nerve and the zygomaticarch.ActaNeurochir(wien).2008 Mar; 150(3):273-8; discussion 278.Epub 2008 Jan 30.

7. SaylamC. Anatomic landmarks of the buccal branches of the facial nerve.Surgradial Anat.2006 Oct; 28(5):462-7.Epub 2006 Jul 13.

8. SaylamC.Localization of the margina mandibular branch of the facial nerve.Cranio Surg.2007 Jan; 18(1):137-42.

9. Schmidt BL, PogrelMA. The course of the temporal branch of the facial nerve in the periorbitalregion. Oralmaxillofac surg.2001Feb;59(2):178-84

10. Gosain A. K. The temporal branch of the facial nerve: how reliably can we predict its path? Plastreconstr Surg.1997 Apr; 99(5):1224-33; discussion 1234-6.

11. Sekiya T, Iwabuchi T, Okabe S, Takiguchi M, Oda N. Facial nerve preservation in the region of the zygomatic arch. PMID: 18231707 (PubMed - indexed for MEDLINE).1990 Nov; 18(11):1029-33.

12. Young Soon Kim. Branching pattern of the facial nerve in the parotid gland.vol 62, no.6, June, 2002.

13. Ekinci N. The study on the branching pattern of the facial nerve of children.PMID:12655222KaibogakuZasshi.1999 Aug; 74(4):447-50.

\section{AUTHORS:}

1. Naveen Kumar B. D.

2. Manjunath C. S.

3. Antony Sylvian D'Souza

\section{PARTICULARS OF CONTRIBUTORS:}

1. Tutor, Department of Anatomy, Hassan Institute of Medical Sciences, Hassan.

2. Assistant Professor, Department of Anatomy, Hassan Institute of Medical Sciences, Hassan.

3. Professor and HOD, Department of Anatomy, Kasturbha Medical College, Manipal.

\section{NAME ADDRESS EMAIL ID OF THE} CORRESPONDING AUTHOR:

Dr. Naveen Kumar B. D,

Tutor, Department of Anatomy,

Hassan Institute of Medical Sciences,

Hassan - 573201, Karnataka.

E-mail: dr.nvngowda@gmail.com

Date of Submission: 13/02/2014.

Date of Peer Review: 14/02/2014.

Date of Acceptance: 19/02/2014.

Date of Publishing: 24/02/2014. 